\title{
Entrevista a Pepetela
}

FERNANDA CASTRO

Universidade da Madeira - Funchal - Portugal 27

18 de março de 2013

\begin{abstract}
Nascido em Benguela, Angola, Artur Carlos Maurício Pestana dos Santos (n. 1941), mais conhecido pelo pseudónimo Pepetela, é um dos representantes da literatura angolana, tendo com uma vasta obra publicada no campo do romance e do conto. Recentemente, Pepetela publicou um novo romance: $O$ tímido e as mulheres (2013). Prémio Camões, em 1997, Pepetela recebeu diversos prémios literários e condecorações que são reveladores do seu talento e da relevância da sua obra. Exemplo disso, em 2014, foi a atribuição do prémio Rosalía de Castro do Centro PEN Galiza e o seu livro A Sul. O Sombreiro foi um dos quinze colocados entre os finalistas do Prémio Literário Correntes d'Escrita 2014. Como consequência da sua formação em Sociologia e da sua participação no governo da pós-revolução, Pepetela questiona e faz os leitores refletir, inevitavelmente, sobre a sociedade colonial e pós-revolucionária, sobre o mundo e a sociedade, criticando mordazmente a descrença dos ideais pós-revolucionários, o nepotismo, o novo-riquismo das elites corruptas que ascenderam ao poder à custa da revolução. A sua escrita (re)constrói a História oficial, denunciando os males da sociedade angolana e da Humanidade em geral. Sem medo de ser considerado um escritor utópico, Pepetela alia a ficção à realidade como forma de observar o mundo e o quotidiano dos Homens de um ponto de vista crítico, questionando o passado e repensando o presente para sonhar o futuro. Como autor que participou na revolução e na (re)construção de uma nova Angola, Pepetela subsidia o real através da sua ficção, construindo espelhos onde o mundo e os leitores se olham num horizonte de possibilidades.
\end{abstract}

FC - Os livros O Cão e os Caluandas, A Montanha de Água Lilás: uma fábula para todas as idades e Predadores, são detentores de um forte cariz humanista e utópico, apesar das disforias descritas. Os finais destes livros são sempre possibilidades de um recomeço e deixam alguma esperança: a buganvília que morre, símbolo da opressão tentacular que rodeia uma casa que é Angola; a sobrevivência da humanidade do lupi-pensador e do lupi-poeta; e a esperança e humanidade de Kasseke e Nacib e o início da decadência de Caposso. Crê ainda na humanidade?

P - Apesar de pouco aprender com a própria experiência, e repetir ciclicamente os mesmos erros, a Humanidade ainda merece um pequeno benefício da dúvida, uma espécie de última oportunidade. Creio cada vez menos nisso, mas tento nos livros mostrar que talvez fosse possível se...
FC - Horácio (66 a.C-8 a.C), um poeta romano cuja obra é constituída por sátiras, odes e epístolas, escreveu que a literatura tem, para além do prazer, uma função didática: "Arrebata todos os sufrágios quem mistura o útil ao agradável, deleitando e ao mesmo tempo instruindo o leitor." Concorda? Para si, quais são as funções da literatura e do escritor na sociedade?

$\mathbf{P}$ - Sim, a literatura tem a obrigação de, pelo menos, dar umas pinceladas realistas da sociedade, na época em que se insere, para conhecimento dos leitores. Com isso, leva as pessoas a pensar nos problemas. Já a resolução dos problemas é da obrigação de outros sectores da sociedade, nem a literatura deve tentar entrar nessa onda. $\mathrm{O}$ escritor pode e deve apontar problemas, divulgar contradições, mas não tem de ser um actor social. Como cidadão poderá, mas que isso não afecte a sua obra como criador. 
FC - A ironia nunca é inocente no discurso ficcional e não passa, definitivamente, despercebida nos seus livros. Retratar inquietudes sociopolíticas ou períodos sérios como o da pós-revolução, ironizando, é uma forma de dessacralizar a realidade apocalíptica através de um sorriso amargo? A ironia é uma arma que desmascara?

$\mathbf{P}$ - A ironia é própria dos angolanos, talvez mesmo dos africanos em geral. Por isso me parece normal que eu a utilize no que escrevo, faz parte da nossa cultura. Por outro lado, há que se relativizar muita coisa, para não se cair no panegírico ou no catastrofismo. Uma pitada de ironia resolve o problema.

FC - As fábulas encerram lições morais. Escolher a fábula, em A Montanha de Água Lilás: uma fábula para todas as idades, foi um método para chegar a vários tipos de leitores, transmitindo um aviso sobre os caminhos da humanidade?

$\mathbf{P}$ - Em primeiro lugar, devo dizer que escrevi esse livro, na sua primeira versão, para a minha filha, teria ela uns seis anos. Muito mais tarde, família e amigos conseguiram convencer-me a prepará-lo para publicação. Adquiriu então a forma actual, que pode servir para menores e para maiores, enviando sempre o aviso de que devemos tomar juízo e não brincar demasiado com a Natureza, porque ela não é uma frágil e compassiva criatura que tudo aceita e perdoa.

FC - Os males que descreve nos seus livros, especialmente a corrupção, a burocracia, a prevaricação, a ambição, a traição, entre outros, mergulham Angola num cenário pós-revolucionário apocalíptico, no entanto, estes males acabam por ser os males da Humanidade. A Montanha de Água Lilás: uma fábula para todas as idades é um hino universal de uma montanha sem lugar, corrompida pela ambição desmedida e holocausto moral de 'ícaros'. É o retrato do mundo?

$\mathbf{P}$ - Como disse atrás, é uma advertência para as pessoas que julgam poder ser irresponsáveis até ao fim. Tenta portanto descrever algumas limitações desta pobre Humanidade, incauta, só olhando para os seus interesses mais imediatos, sem se aperceber que, continuando nessa senda, se condena irremediavelmente. No entanto, talvez haja uma escapatória e algum lampejo de esperança no fim. Sempre há alguém que resiste/sempre há alguém que diz não (estou a citar de memória o meu amigo Manuel Alegre e não tenho a certeza de ser exactamente assim, mas é a ideia).

FC - Thomas More escreveu A Utopia, em 1516, criando um mundo novo para criticar a Inglaterra ociosa e corrupta do século XVI. Considera que A Montanha de Água Lilás: uma fábula para todas as idades poderá ser uma Utopia do século XXI 'às avessas'? Uma inversão em que o objetivo é o mesmo: alertar?

$\mathbf{P}$ - Sim, essa era a ideia original. Talvez tenha tido algum efeito directo sobre a pessoa para a qual foi escrita, que se formou em Biologia e trata de questões ambientalistas. Podemos alargar o alvo e ver a questão como uma Utopia (nem todas têm de falhar, não é verdade?).

FC - Em O Cão e os Caluandas, A Geração da Utopia e Predadores as referências ao socialismo africano são constantes e pertinentes. Considera que foi uma utopia falhada?

P - Não só o socialismo africano, pois no resto do mundo os exemplos abundam dessa utopia que não deu certo. No entanto, era preciso tentar. $\mathrm{Na}$ época, era o objectivo que nos devíamos propor, mesmo se só para atingir parte. Resta às novas gerações analisarem as causas, os erros, para inventarem novos processos, novos objectivos, e fazer dessa experiência qualquer coisa útil aos descendentes.

FC - Sabemos que compilou o livro $O$ Cão $e$ os Caluandas quando ainda estava no governo de Agostinho Neto como Vice-Ministro da Educação. Como foi o processo de compilar este livro, estando ao mesmo tempo em funções políticas? Viu de perto realidades políticas e sociais que desconhecia? Decidiu abandonar a política por causa da escrita e/ou também existiu algum desencanto?

$\mathbf{P}$ - De facto, todas as estórias do livro foram escritas quando eu estava no governo. O livro foi preparado para edição depois de ter saído. Os processos de aprendizagem são longos e exigem avanços e recuos, tentativas e erros. Não tinha grandes ilusões sobre o caminho do país, mas tentava ajudar a manter o barco em cima da água, apesar de todos os furos. O que me impossibilitava a escrita, por falta de disponibilidade. Até que tomei a decisão de me dedicar fundamentalmente à literatura, mesmo se fizesse outra coisa para sobreviver materialmente. Fui dar aulas. Assim pude escrever o que tinha na cabeça.

FC - Sente alguma desilusão com o caminho traçado por Angola depois da independência até aos dias de hoje? O que restou dos ideais socialistas da revolução?

$\mathbf{P}$ - Curiosamente, não sinto grande desilusão. No Mayombe, o personagem Sem Medo já dizia que nunca iriamos atingir o que nos propúnhamos. Talvez metade e já não seria mau. Foi escrito cinco anos antes da Independência. Portanto, eu estava preparado para ficar contente com os $50 \%$ que obtivemos, uma Independência, 
um povo com possibilidade de recuperar a autoestima que o colonialismo the roubou... O resto, a justiça social, a igualdade de oportunidades, isso não foi alcançado. Mas poderia ter sido? Hoje é claro que não era possível, o resto do mundo não deixava, nem nós estávamos preparados.

FC - Como encara o crescente desenvolvimento industrial de Angola face à notícia recente acerca da escassez de alimentos em Angola, Malaui, Lesoto e Zimbabué?

$\mathbf{P}$ - Tem havido crescimento económico em Angola, mas muito pouco desenvolvimento. Não são termos equivalentes. As pessoas não têm aproveitado das enormes riquezas que são extraídas todos os dias, na sua maior parte apropriadas por empresas estrangeiras, uma parte por uma minoria de nacionais pornograficamente ricos, e as migalhas para a grande maioria da população. Mas no capítulo da escassez de alimentos, tudo é muito relativo. Temos de descontar a manipulação feita por interesses que estão por trás dos meios de informação mundiais. Houve alguma carência no ano passado por não ter chovido, mas não se pode falar de fome generalizada, de gente a morrer de fome. De facto não houve, pois o Estado tinha recursos para apoiar, o que fez, usando o Fundo criado para emergências dessas. Este ano choveu bem e o problema de falta de comida não se põe. Aliás (isso vale o que vale...) tem havido por parte dos organismos internacionais encorajamento pelo facto de se estar a vencer a luta contra a fome, sendo Angola apontado como país de sucesso. Não me parece correcto embandeirar em arco, mas também não é justo igualar-nos a países com reais dificuldades de alimentar a população.

FC - Qual é a sua opinião acerca da intervenção de outros países a nível político e económico, ao longo da História, em Angola (Cuba, EUA, China, etc)?

$\mathbf{P}$ - Cuba foi determinante quando as potências mundiais se puseram de acordo para entregar Angola a forças controladas por Mobutu e pelo apartheid sul-africano. Cuba salvou-nos dos nossos inimigos imediatos. Os Estados Unidos nunca perceberam que o seu interesse era ser equidistante e teriam evitado muito drama, para terminar o filme da mesma maneira, com uma parceria estratégica como hoje têm com Angola. Henry Kissinger, quando se reuniu no Sal, em 1975, com Spinola, Mobutu e Botha, para decidir sobre o destino de Angola, colocouse no lugar de honra para terminar no Tribunal Penal Internacional (com os seus parceiros de reunião). Claro que o TPI não funciona para essa gente.

Quanto à China, portou-se muito mal no princípio, apoiando o lado errado, mas cedo percebeu onde estavam os seus interesses. Os chineses vêem mais longe que os outros, sem sombra de dúvida. Apareceram no momento certo, estendendo a mão com créditos, volumosos e quase sem juros, o que permitiu Angola de escapar aos planos de austeridade e reestruturação do FMI e outros organismos correspondentes, que tanto mal têm feito aos povos. Os chineses têm uma vantagem sobre os concorrentes, que hoje mordem as mãos de inveja: eles não escondem ao que vêm, não trazem discursos sobre a amizade e a ligação histórica e afinidades de cultura com os angolanos. Vêm fazer negócio e acabou. Eu prefiro isso à hipocrisia política dos ocidentais.

FC - O leitor, em $O$ Cão $e$ os Caluandas, é levado a crer que o cão pastor-alemão é o mesmo em toda a narrativa quando, no fim do romance, o narrador dá a entender, colocando a dúvida na cabeça do leitor, que, afinal de contas, poderemos ter estado perante vários cães. Este cão imaginado pelos leitores assume, ao longo do romance, vários nomes, entre eles Lucapa, Jasão, Cupido e Leão dos Mares. Porquê a escolha destes nomes?

P - Francamente, não me lembro (já foi há tanto tempo!), das razões para cada um dos nomes. Talvez o contexto próprio o explique. Lucapa certamente não tem qualquer significado, é o nome de um lugar de Angola, hoje já uma cidade. Ou talvez por isso tenha. Dos outros nomes não me lembro.

FC - "Este cão é novo, já nasceu depois da independência (...) - Estes cães serviam para guardar as casas dos colonos, não deixavam entrar nenhum bumbo que não fosse criado da casa. Mordiam os negros, rosnavam aos mulatos, lambiam as mãos dos brancos. - Este não. Já é filho de Angola independente (...) - És ingénuo (...) filho de cobra é cobra (...) Esse cão tem o vírus do ódio ao negro, da desconfiança ao mulato, do respeito ao branco (...)". Porquê um cão pastor-alemão como protagonista que peregrina em $O$ Cão e os Caluandas?

$\mathbf{P}$ - Porquê ser pastor-alemão? Gosto dessa raça, tive vários e tenho saudades deles. São fiéis, corajosos, e só se revoltam com razão. Também permitia algumas brincadeiras, por ser o cão da polícia e exército coloniais, por ter ascendência estrangeira e assim ser passível de sofrer racismo e xenofobia, etc.

FC - A estrutura de $O$ Cão e os Caluandas foi uma forma de fugir ao formalismo do romance que estamos habituados a ver? É um diário de bordo ou de testemunhos da peregrinação de um cão?

$\mathbf{P}$ - Foi a única maneira que arranjei de escrever mais que contos breves na altura em que estava no governo e, portanto, sem saber quando poderia voltar a ter disponibilidade para escrever. Não era possível pegar 
num assunto e continuá-lo, como um romance. Com as interrupções obrigatórias por causa do meu cargo e por realmente trabalhar muito nessa altura, de cada vez que arranjasse tempo para escrever, sairia um estilo diferente. Por isso usei todas as técnicas narrativas, reportagem jornalística, diálogos, diário, conto, crónica, mini-peça de teatro, etc. Assim, seria fácil iludir os rítimos e estilos diferentes. O cão serviria de elemento de ligação. Não foi um plano estabelecido com todos os pormenores à partida. As estórias iam aparecendo e a ideia ficava mais consolidada à medida que escrevia. Durante três ou quatro anos. Depois, quando tive disponibilidade, arranjei as coisas, mudei o sítio de alguns episódios, fiz ligações, reparti o diário da moça, enfim, preparei o livro para ser publicado.

\section{FC - Em O Cão e os Caluandas, A Gloriosa Família} e em $A$ Geração da Utopia confrontamo-nos com a presença de uma planta que assume, nas narrativas, uma simbologia negativa: a buganvília. Existe alguma sabedoria popular ou algum significado ou simbologia que o levou a incluir esta planta nos seus romances?

$\mathbf{P}$ - Não. Mas a um momento dado era a planta usada para fazer cercas, pra impedir as passagens. Na minha cabeça, ficou ligada a um capitalismo que resistia em renascer de forma selvagem por mais que fosse impedido. Bem antes de se ter declarado como depois ficou óbvio para todos, essa imagem já andava na minha cabeça.

FC - O espaço narrativo é importante numa estória, influenciando o comportamento e as características das personagens. Em $O$ Cão e as Caluandas Calpe é a cidade em que o próprio autor se encontra e informa o leitor da constituição e características do romance; Calpe aparece igualmente noutros livros como Muana Puó, A Parábola do Cágado Velho e em O quase fim do mundo, como espaço de acção imaginário do sonho e da utopia. É o fascínio pela mitologia clássica ou o autor, ao colocar-se em Calpe, sente-se na pele de Eurico (Eurico, o presbítero, de Alexandre Herculano) que vê do alto de Calpe a invasão árabe à Península Ibérica mas, neste caso, vê outras invasões e devastações em território africano e olha criticamente através da escrita?

P - Na obra de Herculano aparece a palavra Calpe? Julgava que a tinha inventado a partir de partes do meu nome (Carpe no princípio, de Carlos Pestana; depois abrandei a sílaba inicial). Calpe tem sido a cidade, que vai mudando conforme as épocas. Era a cidade do sonho em Muana Puó (foi nessa altura que foi "inventada"), a neutra e sem vida de "O Cão", a cidade de todos os perigos de "Parábola..." e finalmente uma cidade inventada do nada em "O Quase Fim do Mundo". Usei-a num livro que ainda não apareceu (nem sei se aparecerá), mas a meio dele mudei o nome da cidade, era demasiado parecida com Luanda para não ser designada Luanda.

FC - São vários os escritores africanos que têm o Brasil como referência literária. Em vários livros Pepetela refere o mercado de Roque Santeiro, em Luanda, e em Predadores o nome de uma das principais personagens é Nacib. Pepetela refere que esse facto se deve à telenovela brasileira «Gabriela», baseada no livro de Jorge Amado Gabriela, cravo e canela. Qual é a sua relação com o Brasil? Vê o Brasil como um país irmão?

P - Há muitas relações com o Brasil, não só minhas, mas dos escritores da minha geração, que "aprenderam" a escrever e a ver o mundo a partir dos livros do ciclo do Nordeste brasileiro, que chegavam com toda a facilidade a Angola e nos moldaram, pois descreviam realidades semelhantes às da costa angolana. Nesse aspecto devo dizer que nós quando chegámos a Portugal, nos anos 50, para estudar, ficámos admirados pelo desconhecimento quase total existente aí sobre a literatura brasileira. Pessoalmente, houve essa influência quando era muito novo. Também porque a família da minha mãe foi do Brasil para Angola, no século XIX, e algumas impressões, palavras, estórias, ainda circulavam nas conversas de quintal. As revistas que havia em Angola nos cabeleiros e barbeiros eram brasileiras, "Cruzeiro", "Manchete", "Vida Juvenil". A música preferida era a brasileira. E o futebol que ouvíamos pela rádio. A costa angolana tinha essa relação antiga, provocada pelo tráfico de escravos, que nunca desapareceu totalmente. Depois, passámos a ver o Brasil como o irmão mais velho, o que tinha adquirido primeiro a Independência, era um exemplo. E o Brasil, apesar de ter um regime de ditadura militar, foi o primeiro país do Mundo a reconhecer o governo de Angola independente. Portugal foi o $97^{\circ}$, creio. Coisas que são difíceis de esquecer.

FC - A sua formação, a Sociologia, contribui para a criação dos seus romances?

$\mathbf{P}-\mathrm{Eu}$ estudei Sociologia para ter instrumentos de análise da sociedade e poder basear a minha literatura nisso. Foi uma escolha consciente em que o objectivo último era a literatura. Portanto, contribui e muito. Alguns dizem que demasiado.

FC - Em algumas entrevistas que deu demonstrou vontade de escrever o terceiro Jaime Bunda. Neste momento está a escrever algum livro?

$\mathbf{P}$ - Tenho dito que quem faz dois deve fazer o terceiro. E várias pessoas me perguntam ou pedem o terceiro. Mas não tenho vontade de o fazer, nunca tive. Quem sabe, 
amanhã posso acordar com essa vontade... Sobre o que estou a escrever nunca falo, não sou supersticioso, sou materialista... Mas isso dá azar!

FC - "Agora, leitores, na minha escrita que morre começa a vossa fala." (O Cão e os Caluandas). As intervenções do narrador / autor ao longo do discurso ficcional cativam o leitor. Ao estilo de Sterne ou de Garrett, as intervenções nos seus livros estão imbuídas de ironia, riso, avisos ao leitor e comentários. Porquê auto-retratar-se ou intervir, entregando a função criativa ao leitor?

$\mathbf{P}$ - Já dá um trabalhão danado escrever um livro. E o leitor lê apenas, e quando lhe apetece, sem contribuir em nada para a obra? Não me parece justo. Por isso o incito a continuá-la, pensando nela... E gosto de desvendar e desmitificar essas relações entre personagem, narrador e autor. É uma brincadeira comigo, muitas vezes me pergunto, quem falou isto?, foi o narrador?, qual deles?, ou foi o autor? Quando não sei responder com exactidão, fico satisfeito. Mais ainda quando é um personagem que me joga para o lado e diz, agora sou eu que falo. Eu deixo, feliz...

FC - Em O Cão e os Caluandas o autor jura pela veracidade dos factos narrados porém, até que ponto a História pode afinal misturar-se com a ficção? Gosta de manipular e provocar o leitor, colocando-o perante dúvidas e incertezas que o fazem pensar?

$\mathbf{P}$ - Sim. Antecipei a resposta a esta pergunta na anterior. Hoje devo parecer mais subtil, mais ponderado, mas continuo. Sempre. A dificuldade é encontrar sempre formas diferentes, que não sejam Um copy-paste...

FC - As personagens que criou, nos romances e na fábula que estudámos, são retratos histórico-sociais angolanos da pós-revolução (e não só). Muitas delas representam o novo riquismo, como por exemplo Vladimiro Caposso. Alguma vez recebeu alguma crítica de alguma pessoa que se sentisse retratada nos seus livros?

$\mathbf{P}$ - Sim, alguns têm essa coragem, para depois levarem com a sacramental resposta: "ai é, acha que é você? Não me parece, você é muito mais ridículo. (Ou menos corajoso)". Por causa do nome Caposso, que resolvi escrever com $\mathrm{C}$ e não $\mathrm{K}$ como me seria natural, apenas para depois fazer uma brincadeira com a palavra de ordem do MPLA, a Vitória é Certa, VC, tive uma senhora muito zangada, quando o livro foi lançado, me perguntando como ousara escrever sobre a família dela. É alguém importante. Apenas disse: vá ler o livro; se se sentir retratada ou se tiver alguém da família retratado nele, então deve ficar mais atenta aos comportamentos. Nunca mais me aborreceu.

FC - Os nomes atribuídos às personagens assumem grande importância para a construção interpretativa dos romances. Porquê o nome "Caposso"?

$\mathbf{P}$ - Foi mero acaso, como disse à senhora. Devo ter lido algures ou ouvido alguém com esse nome e achei um nome sonoro, bom para um personagem. Sem nenhum julgamento moral. Há um músico que se chama Kamosso e por isso não pus Camosso, exactamente para não parecer ser alguma alusão ao músico, que admiro muito. Os nomes às vezes são pensados, têm um significado que só eu conheço, por vezes não. Esse é o caso.

FC - Existem, na realidade, muitos "Capossos", "Malongos", "Vítores" aproveitadores da política e da religião?

$\mathbf{P}$ - Este mundo está cheio deles. Porquê Angola estaria isenta? Não acredito em milagres.

\section{FC - Acredita ainda em alguma utopia?}

P - Grande utopia, não. Pequeninas, por vezes. Mas essas deixam de ser utopias. Mas ainda tenho uma vaga esperança que as pessoas aprendam com a História e não passem a vida a repetir os mesmos gestos que só as conduzem para grandes desastres. A Europa, por exemplo, neste momento começa a ter tiques semelhantes à época anterior às duas grandes guerras que provocou. Até no seu relacionamento com os países do Sul começa a adivinharse o seu rancor colonialista, afinal nunca totalmente destruído. Será uma utopia esperar que consiga evitar o que parece inevitável?

FC - Se pudesse mudar o mundo com um livro, o que escreveria?

$\mathbf{P}$ - Não escreveria. Seria de uma grande irresponsabilidade. 